\title{
RESERVA DE CAARAPÓ: AS TENTATIVAS PASSADAS E ATUAIS DE RETEKOHARIZAR O ESPAÇO ${ }^{1}$
}

RESUMO: A presente pesquisa procura entender as transformações no espaço e na sociedade dos Kaiowá de Te'yi Kue. Trata-se de um local ocupado por uma parentela -te'yi, que teve parte e seu território demarcado como Reserva Indígena pelo Serviço de Proteção ao Índio. A partir da demarcação, o Estado atuou implantando políticas públicas com o objetivo de assimilar os indígenas, que reagiram de diversas formas. A reserva serviu também para recepcionar inúmeras comunidades deslocadas de seus territórios. Com o tempo configurou-se uma população com origens diversas, Kaiowá e Guarani, oriundos de diversos locais. $\mathrm{O}$ artigo discute aspectos dessa configuração, da relação com as agências públicas e da sociedade civil que atuam na reserva, bem como o esforço dos indígenas em retomar sua autonomia.

\section{Palavras-chave: Te’yi Kue. Reserva de Caarapó. Kaiwá e Guarani. Terra Indígena.}

ABSTRACT: This research seeks to understand the spatial and social transformations of the Kaiowá of Te'yi Kue. This is a site occupied by a kindred -te'yi, which had part of its territory demarcated as Indigenous Reserve by the Indian Protection Service. From the demarcation, the State acted implementing public policies in order to assimilate the Indians, who have reacted in different ways. The reserve also served to receive many displaced communities from their territories. Along the way set up a population with diverse backgrounds, Kaiowá and Guarani, from various locations. The article discusses aspects of this arrangement, the relationship with the public agencies and civil society that work in the reserve, as well as the effort of the natives in regaining their autonomy.

Keywords: Te’yi Kue. Reserve of Caarapó. Kaiowá and Guarani. Indigenous land.

\footnotetext{
1 Agradeço à professora Fabiane Medina da Cruz por ter contribuído com as minhas ideias para este texto. As suas reflexões foram de extrema importância para esclarecer o conceito de "Retekoharização".

2 Ava Guarani Ñandeva. Falante da língua Guarani fluentemente. Graduado pelo Curso de Licenciatura Intercultural Indígena Teko Arandu na área de Ciências Humanas, turma 2012, da Universidade Federal da Grande Dourados (UFGD). Foi pesquisador do Observatório da Educação Escolar Indígena entre 2013 a 2016 pela Universidade Católica Dom Bosco (UCDB). Pesquisador na área de história indígena, antropologia e filosofia. Endereço eletrônico: elemirs.martinsufgd@gmail.com.
} 
RESUMEN: La presente investigación busca entender las transformaciones en el espacio y en la sociedad de los Kaiowá de Te'yi Kue. Se trata de un lugar ocupado por una parentela -te'yi, que tuvo parte de su territorio demarcado como Reserva Indígena por el Servicio de Protección al Indio. A partir de la demarcación, el Estado actuó implantando políticas públicas con el objetivo de asimilar a los indígenas, que reaccionaron de diversas formas. $\mathrm{La}$ reserva sirvió también para recibir numerosas comunidades desplazadas de sus territorios. Con el tiempo se configuró una población con orígenes diversos, Kaiowá y Guaraní, oriundos de diversos lugares. El artículo discute aspectos de esa configuración, de la relación con las agencias públicas y de la sociedad civil que actúan en la reserva, así como el esfuerzo de los indígenas en retomar su autonomía.

Palavras Clave: Te'yi Kue. Reserva de Caarapó. Kaiwá y Guaraní. Tierra Indígena.

MOMBYKY: Ko jeporeka oheka oikuaa haḡua mba'echapa iñambue tekoha Ava Kaiowá Te'yikue pegua. Ojeje'e hina tekoha oikova te'yi oñemosẽmba akue itekohagui ha ojeguerupa akue yvy ojeporavova SPI rupive. Upe ojeporavo guive yvy mixï. Estado oike ogueru reheve políticas públicas oipota reheve Ava opyta karaicha oiko, upexa verõ jepe ha'e kuera oheka lao pono upexaite opyta, opaxa oha'ã ojeporekavo idireitos re. Jeikoharã ndaha'ei tekoepe oservi ave ñemõi haḡua heta hente ambue tekoha tee guape upepe. Heta ára rire heta etnia ambue oḡuahẽ, Kaiowá há Guarani, heta ambue tekohagui. Ko tembiapo oñe'ẽ upeva rehegua, mba'echapa Ava kuera oiko agencias publicas ha sociedade civil ajapova tembiapo reservape, mba'echapa Ava kuera oñemombarete ogueru jevy haḡua ichupe kuera autonomia imba'e teeva, ojepe'a imi akue heta ára chugui kuera.

Jekoha Ñe 'ẽ: Te’yikue. Reserva Caarapo pegua. Kaiowá ha Guarani. Ava yvy.

\section{Introdução}

O artigo reflete sobre as transformações no espaço e na sociedade dos Kaiowá da Aldeia Te’yikue, município de Caarapó, MS através da análise da culturalidade. Serão avaliados aqui o processo de retekoharização, categoria desenvolvida do Guarani, especialmente do conceito de Tekohá, que significa lugar de morada, no intento de compreender as variações que transformaram as estruturas do território desde a concepção da Terra Indígena, em 1924.

A ideia de desenvolver uma categoria flexionada do Guarani, é estabelecer uma interlocução de interculturalidade entre conceitos do conhecimento hegemônico e ocidental, com estruturas de pensamento, ação, comunicação e gestão territorial que seja de matriz cultural indígena, sob a intenção de dar legitimidade ao modo de pensar Guarani na política. Não apenas, um modo de linguagem, mas, sobretudo, uma estrutura de pensamento político que emana de outras fontes conceituais de política.

Por exemplo, sob a noção de Tekoha, está engendrada a noção de território, entretanto, simplesmente comparar o conceito de Território (geográfico, ocidental) com o conceito de 
Teko, Tekohá (culturalmente centrado), não favorece a compreensão do significado, dentro da política guarani, que tem o conceito de espaço, pertencimento étnico e ocupação das áreas de desenvolvimento da vida, a partir de dentro da lógica originária.

O conceito de Território na linguagem política hegemônica do ocidentalismo compreende o espaço de ocupação da vida como um conceito determinado pela propriedade privada e de direitos individuais de posse (GOTTMANN, 2012). Além de aplicar a sua significação macro-política às delimitações de fronteiras dos estados nacionais, que por meio da noção de soberania de gestão territorial da nação, aplicam controle às "suas" populações, e deste modo, cerceiam povos e comunidades dentro de um limite de governo e gestão cultural e social da vida (SANTOS; SILVEIRA, 2001; SOUZA, 2012).

Sob este conceito de Território, cabe pontuar, a aniquilação dos povos originários e suas políticas de gestão da vida, para converter esses sujeitos em população nacional, isto é, sujeitos que, de uma atmosfera cultural comunitária de sociabilidade e economia, serão civilizados, ou, demudados em indivíduos empobrecidos de suas culturas, expropriados de seus territórios e moldados em acessórios precarizados de um sistema de exploração de trabalho em nome do desenvolvimento nacional. Leia-se, de indústrias e bens de consumo que são geradores de valor que favorecem enriquecimento de um grupo muito restrito, o do capital internacional, que deteriora meio ambiente e vidas em função de um desenvolvimento de tecnologias poluentes e sociabilidades degradatórias do ser (SANTOS \& SILVEIRA, 2001).

Neste contexto, é eminente assinalar as formas de ação de resistência que a sociedade indígena encontrou, neste ambiente, para superar as medidas impostas pela sociedade não índia. Sustentando a sobrevivência frente ao aniquilamento dos povos indígenas que foi carro chefe da política indigenista oficial do estado brasileiro.

Cabe aqui esclarecer que fez parte da política de assimilação dos povos indígenas na civilização brasileira um intenso trabalho de sombreamento da dignidade da pessoa indígena, que, neste trabalho está sustentado pela tese de que o estado brasileiro, para conseguir suplantar as terras indígenas, criou um modelo de tutela jurídica que desqualificou a capacidade da pessoa indígena de compreensão da realidade. Somado à política de educação nas aldeias ter sido, neste período, inexistente, ou a cargo das instituições religiosas, por quanto seja, realizada por meio de um modelo de educação catequética, isto é, ensinar aspectos da religião ocidental, por meio da linguagem indígena, e tão somente esse tipo de educação fora colocado em exercício nas aldeias. 
Neste limite, cabe pontuar a política de aniquilação do estado nacional, que, por intermeio de órgãos de tutela e controle das formas de vida do povo indígena, trabalhou em função de extinguir a cultura e a identidade originária do "território brasileiro". E aqui eu utilizo a expressão território brasileiro sob aspas, para denotar que a política de criação dos estados nacionais no novo mundo (ou nações coloniais), foram projetos de sobreposição de territórios.

Analise necessária para pontuar a impreita do trabalho aqui esboçado, no que tange, a convergência do sentido para as categorias que aqui eu mobilizo, tekoharizar, ou retekoharização. Flexões semânticas do termo guarani Teko e Tekohá, como haja vista, citado acima, produzem bastante sentido na ilustração do movimento de retorno e recolocação das parentelas por volta dos limites da reserva de Tei'y Kue, transcendendo as limitações que foram conferidas pelo SPI para a expansão da comunidade guarani, por entre os seus territórios ancestrais.

O método que cabe aqui utilizar, é um método muito simples, vamos discorrer a formação do espaço da reserva e destacar as alterações na configuração social e física, desde a sua formação. Para este método, é que damos o nome de retekoharizar. Um movimento, ao mesmo tempo geográfico e político, uma vez que mobiliza noções de ampliamento do espaço, combinado pelo ato simbólico de exercício da autonomia indígena em, ao contrário da visão de tutelados, perceber a expropriação e agir em prol da recuperação do espaço que lhe é sagrado e natural.

A hipótese que desenvolvemos como pano de fundo é de que o sistema sócio-político instituído, não foi eficiente em cumprir com seu propósito de ‘extinção' dos povos originários do Brasil. Por consequência, essa política assimilacionista despertou nas comunidades indígenas o desejo de retorno à ancestralidade de seu modo de vida, o que podemos concluir com tomada do caminho de volta para aldeia, ou o que ficou conhecido na literatura política do movimento indígena, como retomada.

Observamos que a política de cerceamento territorial, que perdurou até o final do século $\mathrm{XX}$, foi revertido em retekoharização, ou seja, o movimento quando vários grupos começam a se organizar para reocuparem seus territórios. A exemplo deste ampliamento territorial pode ser observado nas extensões da aldeia, que surgiram em forma de retomada. Foi o que aconteceu, por exemplo, com Jarará (1986), Taquara (1999). Km 20 (1999), Guyra Roka (1999) e, finalmente, várias ocupações no entorno da reserva de Caarapó (a partir de 2013). 
Sendo assim, esse movimento de parentelas no sentindo reocupar antigos tekoha é aqui nomeado por mim de retekoharização, o que implica em recompor coletivos, ativando vínculos de sociabilidade entre famílias e também com os espaços de ocupação tradicional. Tentaremos discorrer essas características da categoria de retekoharização no decorrer deste trabalho.

\section{Breve histórico do tekoha Te’yi Kue e da implantação da reserva de Caarapó}

A reserva indígena Te'yikue de Caarapó foi demarcada em 20 de novembro de 1924 pelo Decreto da Presidência da República, com 3.600 hectares. A história da reserva indígena Te'yikue teve o mesmo resultado de confinamento das demais reservas demarcadas pelo SPI entre 1915 e 1928, pelo Decreto da Presidência da República, com áreas que não passavam de 3.600 hectares, um retângulo de quatro quilômetros por nove, denominado de Posto Indígena José Bonifácio.

Segundo Smanioto (2009), em seu estudo, atualmente a área da reserva tem 3.594 hectares. De acordo com Schaden (1974), no ano de 1949 a população variava entre 200 e 300 indígenas, majoritariamente da etnia Kaiowá. Nos levantamentos realizados pelo SPI, em 1965 a população era de aproximadamente 382 pessoas. A FUNAI no ano de 1987 registrou um número aproximado de 1.467 pessoas vivendo na reserva.

O aumento numérico da população é explicado pelo nascimento de novos membros e pela vinda de novos moradores de antigas aldeias tradicionais que foram expulsos de suas terras para a abertura de fazendas. É importante destacar que era comum no período, as reservas receberem indígenas que eram expulsos de seus tekohas originais.

O confinamento ou a acomodação compulsória ocasionado aos povos Guarani e Kaiowá desta região se intensificou a partir da década de 1950, provocando uma superpopulação e sobreposição de famílias extensas na terra indígena Te'yikue. $O$ povoamento dessa região, somado ao extrativismo da madeira e a intensificação das atividades agropecuárias, mais especificamente nas décadas de 60 e 70, provocaram a degradação ambiental, o enfraquecimento do solo e a troca de vegetação nativa por uma vegetação exótica (colonião e braquiária) nas terras indígenas demarcadas. Esses e outros fatores impossibilitaram as práticas culturais e religiosas dos povos guarani e Kaiowá, em especial, o plantio tradicional das roças agroecológicas tradicionais, gerando dificuldades na produção de alimentos na aldeia e nas práticas dos rituais. 
Já passaram pela região muitos pesquisadores e outros muitos ainda passarão. O desafio de entender e pesquisar um tekoha específico a partir da perspectiva de confinamento, fruto do processo de colonização requer muita atenção, reflexão, dedicação e ética. Muitas histórias ricas foram invisibilizadas ao longo dos anos, devido o contato com a sociedade envolvente, nesse caso os karai ou mbairy ${ }^{3}$. Por isso, minha obrigação com esta pesquisa, é iniciar uma pequena história das muitas que existem sobre Te’ýikue.

Em contrapartida aos outros trabalhos já desenvolvidos sobre o tema, o texto quer contribuir com uma metodologia que coloca em evidência a perspectiva da agência do sujeito indígena, no processo de conscientização da perda de seu território e consequentemente, da ação direta da retomada de seu território, iniciando um processo de autodemarcação de suas terras.

O processo de autodemarcação é a resposta de anos de morosidade do Estado brasileiro em reconhecer os direitos indígenas de acesso e permanência ao seu território. Trata assim de uma devolutiva para o sistema de justiça que, em aliança com setores ruralistas, embargam o processo de demarcação de territórios. Ato que fere a constituição federal brasileira, coloca o país em negligência aos tratados internacionais de Direitos Humanos e prevarica a lei do indigenato ${ }^{4}$, que estabelece o direito ao território indígena um direito natural, ou seja, um direito que precede à lei da propriedade.

O nome da reserva indígena Te 'ýikue é a junção de ñe ’ẽ Te yyi, que significa família composta por crianças, jovens, anciãs, sábios, sabias, parteiras, ñanderu, ñandesy, homem e mulher; e kue como sufixo da palavra para indicar o passado, ou aquilo que já foi, podendo ser traduzido como aldeia antiga. Os mais velhos da aldeia, contam que este lugar sempre foi um tekoha tee dos indígenas, onde existia te 'ýi organizada em uma óga kapi'i ou óga jekutu (casa feita de sapé), onde o rezador morava e rezava, havendo assim, uma intervenção política e religiosa conforme a orientação do Tupã Guasu.

Quando o engenheiro do SPI esteve por aqui para delimitar a terra ouviu de muitos indígenas a palavra te'ýi. Durante a minha pesquisa tive a oportunidade de ouvir muitas histórias e conselhos dos mais velhos, que falaram para mim da importância de repassar pelo menos uma pequena parte para as crianças saberem como era a vida dos parentes antigamente.

Em certo momento veio uma epidemia que dizimou todos os moradores desta aldeia. Outra versão afirma que um Ñanderu ("nosso pai", cacique ou rezador) rival mandou um feitiço do mal para aquele cacique, como forma de teste, porque havia

\footnotetext{
${ }^{3}$ Termo com o qual o povo kaiowá denomina o branco, ou o não índio, da sociedade envolvente. O termo tem uma conotação pejorativa e é tomado do comportamento do não índio em relação a terra. Neste contexto, o termo pode significar o invasor, ou, o destruidor, o genocida.

${ }^{4}$ Mais informações em: http://www.funai.gov.br/index.php/2014-02-07-13-26-02.
} 
disputa entre os dois. Em tal circunstância, um dos caciques não era muito preparado e deixou escapar o feitiço do controle, espalhando doença em toda aldeia por muito tempo e, consequentemente, dizimando a população. Muito tempo se passou e ninguém se atrevia a entrar nessa aldeia com medo da doença e, por isto, o lugar foi chamado de "lugar onde o Te'ýi morou". Passaram-se vários anos para retornar outros moradores e repovoar o lugar. (BENITES, 2014, p. 42).

Durante a minha pesquisa, muitos relatos que eu ouvi condiz um pouco com o relato do autor supracitado. Uma Kaiowá de 80 anos, que pediu para que o nome não fosse divulgado, salientou que essa aldeia sempre foi dos indígenas.

Che mixĩ guive voi, ahendu va'ekue che maxu ha ituja vevagui ko jaikoha ñande
mba'eha vointe. Heta araka'e oi ka'aguy, mymba ka'aguy, guyra, pira. Uperõ ahai
kuaa rire ra'e, heta jehai pyre ajapo ramo'ã raka'e. Soke areko ko'angaite peve che
akãpe pe ñemombe'upy. Upeagui ko'anga hina ambohasa ndeve. (fala colhida
durante pesquisa de campo em outubro de 2013).
Tradução: Desde pequeno eu ouvia da minha vó e dos mais velhos que esse lugar
onde estamos morando era nosso mesmo. Tinha muito mato, animais silvestres,
pássaros, peixes. Nesta época se eu soubesse escrever eu escreveria muita história e
relatos. Contudo eu tenho até hoje na minha memória essa história. Por isso estou
passando a você agora.

Conforme o relato, naquela época poucas pessoas moravam na aldeia, tudo era mato fechado, com muita caça, pesca e frutas nativas. Neste relato percebemos a importância da figura do mais velho para passar a história da aldeia e saberes indígenas ao mais novo ou para família. Nos dias atuais temos que ouvir todas as histórias que os mais velhos contam, como ela mesma afirmou "hoje em dia quase não tem mais pessoa que sabe a história, porque muitos já morreram e algumas pessoas não procuraram saber com essas que já foram" (idem).

Segundo a Kaiowá, havia muito respeito e união entre os indígenas, o trabalho era tudo na base da coletividade. Quando um grupo familiar indígena ia fazer roça os trabalhos eram em mutirão ou puxerõ (trabalho coletivo). Todas as funções de trabalho (carpir, arrancar toco, queimar madeira, plantar, etc) são divididos.

Os meninos e as meninas seguiam a tradição de sua cultura e eram ensinados pelos pais conforme a orientações dos xamãs. Toda noite os rezadores se reuniam na casa do seu compadre para rezar.

Hoje em dia, os indígenas dependem de políticas compensatórias (cestas básicas) do Governo (do Estado) para sobreviver. Essa realidade provoca a saída massiva dos homens da reserva para trabalhar nas usinas de álcool. O trabalho na Usina Nova América garante a subsistência da família, porém o afastamento do homem tem gerado inúmeras dificuldades no seio familiar, dentre elas a sobrecarga de trabalho para as mulheres e na educação dos filhos e filhas, assim o papel dos ñanderu no seio familiar foi esquecido. 
As principais atividades econômicas estão relacionadas à agricultura familiar, "bicos" nas fazendas circunvizinhas da aldeia e o trabalho assalariado na Usina Nova América. Em decorrência do baixo nível de escolarização e pouco preparo para o mundo do trabalho em setores especializados, a maioria dos empregos ofertados estão relacionados basicamente aos serviços braçais, como o plantio, manutenção e corte da cana-de-açúcar.

As famílias que procuram sobreviver através da agricultura familiar vêm passando por algumas dificuldades, pois o solo tem perdido seus nutrientes em decorrência do constante uso do solo e das queimadas. Como resultado de anos de exploração a terra acaba tendo pouca produtividade agrícola.

Outro fato que implica diretamente na produção é a falta de rezadores para orientar os agricultores no controle de pragas, pois o ritual serve para afastar grande infestação de formigueiros existentes na aldeia. Tal ocorrência segundo relatos oral dos próprios moradores acontece porque a reserva não é seu lugar, também não será um lugar para manter o teko.

Embora o trabalho realizado nas usinas de álcool e açúcar não seja o esperado, haja vista o alto nível de esforço físico empregado durante as horas trabalhadas é através deste emprego que boa parte das famílias tem acesso aos bens de consumo. É visível a crescente aquisição de móveis e eletrodomésticos como: TVs, máquina de lavar roupa, celulares, motos, automóveis entre outros bens. O uso do aparelho de TV está presente nas casas de muitas famílias.

Apesar da difusão e o acesso aos meios de comunicação, ainda boa parte da população que reside na aldeia Te'yikue não possuem tal aparelho. Esta questão é reflexo do nível econômico das famílias e do crescente número de pessoas que se convertem a doutrinas religiosas que não permitem o uso de TV nas suas residências. O Pastor ressalta que a TV traz maldição para o lar e família.

É necessário destacar que desde a chegada da igreja pentecostal Deus é Amor, em 1924, tem crescido o número de pessoas que começaram a frequentar a igreja, porém ao longo dos meses muitos acabam abandonando a religião. No início era usado lamparina para fazer oculto, a casa era ramada, construída com a ajuda dos próprios fieis. Nessa época não havia caixa de som e nem microfone.

O uso de inúmeros aparelhos eletrônicos só foi possível, graças à expansão da rede de energia elétrica na aldeia, que antes se limitava a um reduzido número de famílias. Com o Projeto Luz Para Todos, alavancado principalmente a partir do ano de 2005, praticamente todas as famílias foram atendidas com a eletricidade e inúmeros aparelhos foram sendo 
adquiridos. As igrejas ganharam mais força, pois compraram caixa de som, microfone e boa iluminação no seu interior. Com os investimentos de novos equipamentos e a construção de igrejas, o papel de ñanderu sofreu muitas transformações. O ñanderu que era chefe de parentela, referência religiosa e política, passou a dividir prestígio com os pastores e o capitão.

Na comunidade há um Templo da Igreja Deus é Amor, uma das maiores da aldeia, há também na Região Bocaja, I Igreja de Deus Pentecostal, porém é um templo pequeno.

Em relação à saúde, a comunidade é atendida por dois postos de saúde: Zacaria Marques e Jorge Paulo. Nestes postos há atendimento médico e odontológico para uma população de 4.699 indivíduos, e 1169 famílias, segundo dados da SESAI (Secretaria Especial de Saúde Indígena) referente ao ano de 2014. É importante destacar que tais postos são insuficientes para atender à crescente demanda da comunidade.

Em relação ao atendimento, há um médico atendendo exclusivamente o posto de saúde central e outro que atende exclusivamente o posto de saúde localizado na região do Saverá, havendo ainda um terceiro médico na especialidade de pediatria que atende os pacientes no posto de saúde do centro e Saverá.

Além dos médicos há na comunidade duas enfermeiras, uma em cada posto de saúde, 16 agentes de saúde, sendo 10 atendendo as famílias que se enquadram no posto de saúde central e 06 que atendem as famílias do posto de saúde localizado na região Saverá.

Para dar suporte aos pacientes que são encaminhados para outras especialidades ou tratamento médico hospitalar na cidade de Caarapó ou outros hospitais do estado de Mato Grosso do Sul, há oito viaturas e cinco motoristas que realizam a locomoção destas pessoas.

Quanto ao abastecimento de água potável, ainda observa-se que nem todas as famílias são atendidas com rede de água encanada, sendo que muitas pessoas ainda utilizam água de poços ou até mesmo de nascentes, o que pode ocasionar sérios problemas de saúde, pois a água pode estar contaminada. Segundo levantamento realizado pela agente da AISAN (Agente Indígena de Saneamento), 81,7\% das pessoas possuem rede de água encanada em suas residências, $11,5 \%$ possuem poços enquanto que $6,7 \%$ ainda utilizam águas de nascentes para suprir suas necessidades.

A comunidade local conta ainda com um posto do CRAS (Centro de Referência a Assistência Social), com uma assistente social e uma psicóloga, que orientam e prestam assistência as famílias e indivíduos que se encontram em estado de risco social. 
As habitações são em sua maioria compostas por casas de tijolos, as casas tradicionais construídas com madeiras e cobertas de sapé já são minoria. Nota-se um crescente processo de construção de moradias em alvenarias, cobertas em sua maioria por telhas de amianto. $\mathrm{O}$ aumento do número de tais habitações dentro da aldeia deve-se em parte por programas habitacionais, impulsionadas pelo Governo Federal em parceria com o Governo Estadual que vem aos poucos incluindo a comunidade indígena em seus programas.

Em relação ao lazer, a comunidade indígena da aldeia Te’yikue conta com poucos atrativos. Não existem praças de lazer e as atividades diferenciadas são em sua maioria promovidas pelas escolas existentes na aldeia. Na comunidade há um Templo da Igreja Deus é Amor, talvez seja uma das maiores da aldeia.

\section{A liderança tradicional: suas características, suas funções na organização dos novos assentamentos}

As lideranças tradicionais chamadas pela maioria dos Guarani e Kaiowá de ñanderu e as ñandesy são os pilares da cultura. Essas pessoas conseguem manter através dos rituais de xamanismo uma relação suficientemente próxima com as divindades. O ñembo'e (rezas) e jehovassa (bendições) têm poder profilático e fertilizante. Serve de cura para doenças, como por exemplo, dor de cabeça forte, feridas incuráveis, picada de cobra, etc. Quando as crianças nascem, havia o batismo com ñanderu, havia um processo de preparação com os pais da criança e o rezador dava a sua orientação e várias regras para o resguardo para a saúde da mulher e da criança, uma delas é não deixar que qualquer pessoa veja o recém-nascido antes de sete dias. A mulher deve permanecer dentro de casa, pois assim, nenhum espírito do mal se aproximará dela e do bebê.

Não se pode negar que os rituais como práticas religiosas, sempre foram praticados pelos Guarani e Kaiowá. Em qualquer situação os indígenas faziam rezas, por exemplo, quando iam caçar, pescar; as rezas serviam para ter sorte e afastar os espíritos maus.

As funções e atuações dos xamãs ou ñanderu e as ñandesy nos tekoha eram vistas com o maior prestígio, porque ambos impediam a ação dos espíritos maus para desestruturar e romper a religião indígena.

Existem vários jara ou seja, donos ou protetores dos seres da natureza que os indígenas relacionam e respeitam, assim, temos os jara para: yvy pu'ã itagui (morros de pedra), pântanos, ka'aguy (florestas), temity (plantas agrícolas) e os diversos tipos de mymba ka'aguy (animais silvestres) e rymba (animais domésticos). Para cada dono é atribuído um 
respeito muito grande, pois acredita-se, que quando um indivíduo desrespeita as regras narrado pelo xamã, sofre grande consequência. No entanto, é necessário que haja respeito e comunicação entre eles e isso só é possível através das rezas. Sendo assim, podemos entender que tem uma relação de referência, respeito e dependência.

\section{A capacidade xamânica é imprescindível para o homem improvisar um estilo de vida terreno, através dela o homem adquire conhecimentos junto aos diversos jara, igualmente xamãs. É também através do xamanismo que o homem espera superar sua condição atual, recuperando o destino do qual se separou em tempos imemoriais. (PEREIRA, 2004, p. 235).}

Percebemos através dessa fala do autor que a capacidade xamânica consegue o equilíbrio de contato com os jara, assim procura desenvolver vida de qualidade.

É relevante ressaltar que a importância e as funções dos rezadores nas comunidades indígenas estão associadas aos saberes sobre: preparação e nomes de plantas medicinais, rezas, benzimentos, práticas agrícolas, arte, pintura, etc. Portanto, o rezador assume o papel do xamã, mantendo comportamento necessário para receber dos deuses, a sabedoria para ensinar, resolver os problemas e para buscar cura.

Quando as pessoas ficavam doentes procuravam os rezadores e as rezadoras para buscar a cura e sempre conseguiam. Para que isso seja possível, segundo os xamãs, o mais importante é seguir regras rigorosas, regras essas, que foram fundamentais para eles se tornarem xamãs. Sendo assim, conseguem ganhar respeito e admiração pelo trabalho com as pessoas, tanto que sofre murmuração por parte da família.

Percebemos ainda que mesmo durante a sua formação de xamã o yvyra'ija já é ensinado a exercer um papel de liderança na comunidade. As atuações das lideranças espirituais e religiosas tradicionais são fundamentais para o desenvolvimento social no interior das aldeias. Na concepção espiritual Guarani e Kaiowá a reza protege, dá segurança a te ýi (a família), para que assim, os espíritos maus e de condutas negativas, não manipulem o teko porã do povo.

O rezador Florêncio Barbosa, conta que durante bastante tempo na aldeia acontecia as rezas e que ao final da tarde as famílias se reuniam para ir do outro lado da região para fazer o jeroky. Antes de iniciar jeroky, as pessoas sentam entre o conhecido para conversa, nessa conversa fala-se sobre plantação, problema familiar, plantas medicinais, caça, pesca, problemas internos da região.

\footnotetext{
${ }^{5}$ Rezador aspirante, ou, aquele que está recebendo preparo para ser um nhanderú.
} 
Segundo Florêncio Barbosa, os rezadores se reúnem e fazem o jehovasa, os rezadores perguntam se alguém está sentindo algum problema de saúde, caso alguém estiver doente, imediatamente já é levado dentro da casa para falar particularmente com rezador e para depois receber durante alguns minutos um ritual especifico para o problema. Continuando o procedimento, se faz uma reza bem forte para espantar o espirito mal do meio da roda e assim conseguir trazer a alegria durante e depois da festa.

O prestígio, no entanto, como se percebe conforme essa narrativa, baseia-se principalmente nos laços de parentesco por ele estabelecidos positivamente. Inclui-se aí também laços de afinidade política, bem como em sua capacidade de aglutinação por meio de seu papel de aconselhador, mediador e distribuidor de dons, sabedorias e esperança. É nesses casos que poderia acontecer, por exemplo, a poligamia característica das lideranças no passado. O bom líder precisava ser capaz de planejar para oferecer muitas festas e nesse caso, conta com o papel da mulher. Se há um bom número de mulheres, pode-se oferecer muita chicha. As mulheres indígenas favoreciam o estabelecimento de alianças por intermédio de casamentos. Conforme nosso interlocutor, geralmente na festa havia 90 a 100 pessoas, conforme na leitura do texto de Brand (1997), o número de pessoas na reza era bem elevado.

(...) tinha às vezes cinqüenta, oitenta, cem naquela localidade (...) só os parentage, é combina mais bem (...) por que tem aquele próprio cacique (...) os cacique falava aquilo e falou aquilo e acabou. [...] tinha sessenta, tinha cem, tinha cento e pouco, só grupo de família ali e todos obedecia aquele mais velho, o cacique. É o tronco, né (BRAND, 1997, p. 230-231).

Percebe-se nessa afirmação do autor, sobre a importância da aproximação e intervenção política dos mais velhos para compactuarem a mesma ideia de boa vivência. A boa vivência acontece porque cada pessoa já conhece os critérios e o sistema da organização do núcleo familiar. Tanto que quando comete alguns delitos recebe castigo de acordo com as leis, estabelecidos pelos mais velhos, nesse caso o rezador e demais sábios. Primeiramente recebe ñembo'e até amanhecer, ao amanhecer recebe ñemoñe'e para tirar ñapiraguai (braveza) (kondaindaí- teko poxy). Nesse conselho, o sujeito recebe um tipo de terapia espiritual e psicológica, como se redimir perante seus erros, saber respeitar os seus adversários e também para que os espíritos de um bom ava ${ }^{6}$ (ava etê), não se distanciem dele.

No yma guare sistema de lideranças, a figura principal era o chefe de parentela sempre é alguém que reza, esse líder tem e possui a capacidade de reunir em torno de si um significativo número de núcleos residenciais de pares (PEREIRA, 2004).

\footnotetext{
${ }^{6} \mathrm{AVA}$ corresponde à pessoa ou o sujeito guarani, assim como denominam-se entre si, pela cultura.
} 
Com o tempo muitos líderes religiosos importantes resolveram sair dos limites da reserva, pois percebiam que o projeto apresentado pelo Estado não seria adequado para a família continuar praticando a sua cultura e religião. Por isso, quando perguntamos para pessoa da comunidade se conhecem alguém que rezava muito, simplesmente ela responde que a maioria saiu porque não se adequava ao ambiente e ao espaço da reserva, ou seja, ao confinamento.

Ao longo da década de 1924, muitas lideranças espirituais e religiosas mostraram aos seus pares da Te'ýikue a importância das rezas, segundo a afirmação deles, só assim mbarete (força), pytyvõ (ajuda) viria dos deuses, para continuar mantendo sua cultura, língua, religião, o respeito pela natureza, respeito pelos rezadores. Acredita-se que através do ñembo `e o ñanderu que consegue se comunicar com os deuses que pertence a sua cosmologia. Essa força que vem dos deuses encoraja os indígenas para continuarem sendo indígenas, mesmo com tanta violência e preconceito durante a criação das reservas. Eles encorajam-se para continuar lutando para existir e continuar mantendo sua maior riqueza, a cultura, resistindo à violência imposta pelos colonizadores. É fundamental lembrar que os Guarani e Kaiowá da Te'yikue foram sendo atropelados violentamente pela onda de chegada dos karai, principalmente de origem gaúcha. Outras fazendas se instalaram da mesma forma: eles (os karai) chegavam, viam que não tinha ninguém (aparentemente ${ }^{7}$ ) na terra, construíam casas, cercavam o terreno e auto afirmaram os donos do lugar.

Segundo vários autores (BRAND, 1997; THOMAZ DE ALMEIDA, 2001; MURA, 2006; BENITES, 2009), iniciou-se, principalmente a partir das décadas de 1940 e 1970, um período de expulsão e dispersão das famílias indígenas Guarani e Kaiowá de seus tekoha guasu (territórios). Essa nova "situação histórica" foi marcada tanto pelo fim do monopólio da Cia. Matte-Laranjeira quanto pelo aumento do loteamento da região, que é quando se abre a região para a instalação de inúmeras fazendas privadas sobre os tekoha guarani e kaiowá.

Os elementos sociais significativos dos tekoha forçados a deixar foram sendo, aos poucos, deixados de lado pela sua inviabilidade em um novo contexto. Assim, surgiram, novos arranjos sociais, constitui-se, então, outras estratégias políticas e negociações entre as famílias extensas. O surgimento de configurações sociais novas, pouco levou conta a estrutura social Kaiowá e Guarani, e isso modificou a relação social promovida pela culturalidade deste

\footnotetext{
${ }^{7}$ Aparentemente, porque os indígenas não são considerados como pessoas na sua integralidade. Vide estatuto do índio, que trata-nos como "relativamente capazes", e por isso deveríamos ser "tutelados por um órgão indigenista oficial". Vide Lei 6.001, promulgada em 1973.
} 
povo. Assim sendo, novos arranjos estratégicos entre as parentelas no interior da reserva foram necessários, frente aos demais grupos familiares ali presentes.

Esta relação, provocada pelas agências de políticas externas é pautada pela homogeneização de vários núcleos familiares diferentes, determinando outros conceitos de comunidade e de família.

\section{A atuação do órgão indigenista oficial SPI/FUNAI}

Sua fundação dos órgãos indigenistas oficiais se deu em um período altamente crítico e violento para os povos indígenas. Diversas frentes de expansão de projeto de dominação ao longo de todo o país praticavam violências contra os indígenas. O então diretor do Museu Paulista, Von Ihering, defendia o extermínio dos índios que resistissem ao avanço da civilização, promovendo grande revolta em diversos setores da sociedade, apesar de tudo. Em 1908, o Brasil fora publicamente acusado de massacre aos índios, no XVI Congresso dos Americanistas ocorrido em Viena (RIBEIRO, 1979; CARNEIRO DA CUNHA, 1987).

Foi neste contexto que se deu origem ao Serviço de Proteção aos Índios e Localização de Trabalhadores Nacionais (SPILTN), que garantiria tanto a proteção e integração dos índios, quanto a fundação de colônias agrícolas que se utilizariam da mão-deobra encontrada pelas expedições oficiais (Decreto $\mathrm{n}^{\mathrm{o}}$. 8.072, de 20 de junho de 1910). $\mathrm{Na}$ base de assimilação destas funções estava o conceito de que o 'Índio' era um ser em estado transitório. O seu único destino seria tornar-se trabalhador rural ou proletário urbano.

O formato da política de administração dos índios pela União foi inserido no Código Civil de 1916 e na lei $\mathrm{n}^{\mathrm{o}} 5.484$ de 27 de junho de 1928, que afirmaram sua relativa incapacidade jurídica e o poder de tutela ao SPI. Estes mecanismos, portanto, partiam de uma noção extremamente negativa e genérica de 'Índio' ${ }^{8}$. De fato, não foram formulados critérios objetivos diferenciados que pudessem dar conta de atender a diversidade de situações problemáticas vividas pelos povos indígenas no Brasil. Por um lado, visava proteger as terras e as culturas indígenas, por outro, a transferência territorial dos "indígenas nativos" para liberar áreas destinadas à colonização e a imposição cruel de alterações em seus modos de vida. Esta situação foi chamada pelo antropólogo João Pacheco de Oliveira (1987) de "paradoxo da tutela".

\footnotetext{
${ }^{8}$ Índio, termo racista para delimitar um povo por estereótipos do senso comum atribuídas perversamente. Entre a significação do termo, (coletado do senso comum), encontramos as correspondências: bêbado, preguiçoso, burro, traiçoeiro, insolente, porco, miserável, indigente. E outros arsenais de termos pejorativos que recolhemos dos enunciados que articulam índio dentro de uma frase. Quase todos esses enunciados já foram atribuídos a mim, ou alguém da minha família.
} 
Nesse contexto, destaco a atuação do Serviço de Proteção aos Índios (SPI), órgão criado em 1910 e que desde o seu início teve ampla atuação entre os Guarani e Kaiowá. Sua principal medida fundiária que deixou marca muito triste foi a criação de oito pequenas reservas/áreas de acomodações indígenas destinadas aos Guarani e Kaiowá, a menor com 668 hectares e a maior com 3.594 hectares. Hoje todas têm uma superpopulação acirrando vários tipos de conflitos, incontáveis problemas sociais e graves violações de direitos humanos por parte da sociedade Karai e política pública destinada às comunidades que foram confinadas. Destacamos em verde as reservas demarcadas no Sul do Estado de Mato Grosso do Sul. Este mapa, tive acesso em 2012, quando o professor Levi Marques, na aula de antropologia passou sobre a criação da reserva, por ser curioso pesquisei no site sugerido pelo professor.

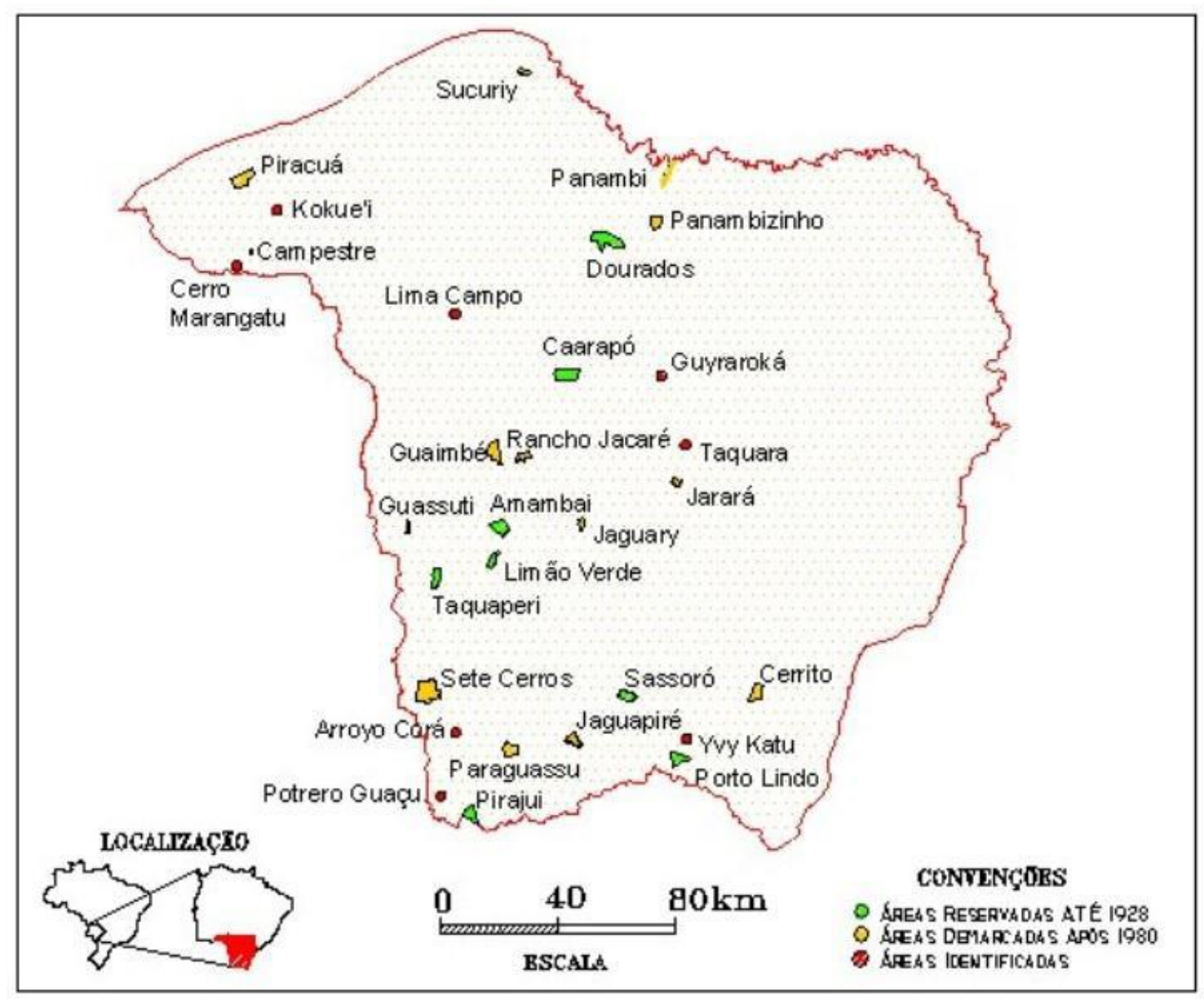

Fonte: http://www.trilhasdeconhecimentos.etc.br/mato_grosso_do_sul/guarani.htm, acessado em 14/11/2012.

O ponto de vista mais negativo que esse órgão praticou contra os índios foi de propagar que não são capazes de discutir e planejar seu futuro, portanto, seria importante impor regime de tutela como proteção. De alguma maneira isso tudo serviu para liberação de territórios indígenas para colonização, ao mesmo tempo em que reprimia práticas tradicionais e propagava uma escolarização que alterava o sistema produtivo indígena. 
A iniciativa desde o princípio como fio condutor estava voltada para a pacificação de comunidades indígenas em áreas de colonização. Os principais Estados que progressivamente foram instaladas equipes apoio e postos indígenas são: São Paulo, Paraná, Espirito Santo, Mato Grosso do Sul e demais regiões.

Desde então, buscou-se apoio para que juntos pudessem garantir reservas (terras) para sobrevivência cultural, religião e física dos indígenas. Muitas pacificações foram realizadas, ressalto as regiões que foram atropeladas por isso, como a dos índios Kaingang em São Paulo e no Paraná, e dos índios Urubu-Kaapor no Maranhão.

Muitos índios morreram no pós-contato, pela doença, fome e falta de assistência. Exemplo disso é do que ocorreu com os kayapo do Pará após as atrações negativas violentas comandadas pelo sertanista Francisco Meirelles no final da década de 50.

É possível afirmar que o SPI foi formado para dar continuidade as alegações negativas civilizacionistas ou legados projetados coloniais. Sua metodologia de atuação, formado a partir de doutrinas positivistas, incorporou técnicas missionárias tais como: distribuir presentes, vestir os índios e ensinar-lhes a tocar instrumentos musicais ocidentais, depois ensinar-lhes a Bíblia com intuito de incutir-lhes a palavra do ocidente.

Muitos projetos destinados as comunidades indígenas, por exemplos, criação de vaca na Te'yikue, ocasionou muitos conflitos de disputas, alguns acharam que era desnecessário esse tipo de projeto que causaria impacto na natureza, mas alguns grupos que eram considerados mais fortes na reserva, não interpelaram os moradores de toda a aldeia, forjaram um consenso restrito que envolveu algumas 'lideranças' junto responsável do SPI e já começaram erguer cercas dentro da aldeia.

Cabe observar nessa parte que o SPI buscou mecanismo sem questionar a organização de todos da reserva, só alguns grupos eram escolhidos para esse diálogo de negociação, sendo que a família que mora na periferia da aldeia tem também seus anseios específicos e políticas diferentes, portanto nessa situação importa prevalecer o dialogo maior.

Esta situação de "confinamento", como define Brand (1993), gera enormes dificuldades de convivência que se expressam em conflitos políticos, econômicas e religiosas, na exaustão dos recursos naturais e na dificuldade de colocar em operação as formas de sociabilidade próprias a sua cultura. Nas condições de vida encontradas na reserva, muitas famílias perderam cabeça de parentela, é o caso da morte dos anciões e as anciãs, ou Ñanderu e a $\tilde{N}$ andesy. 
Mas, a forma de condução da política na reserva Te'ýikue não parou por aí, tanto no princípio o chefe do posto não conseguia atender a demanda, aí se cria a figura do capitão a função dele era a de articular, coordenar e controlar o conjunto do espaço geográfico da população de cada reserva indígena, não foi diferente na reserva supracitada essa função de poder que foi atribuído a ele. Vale lembrar que o capitão era escolhido arbitrariamente pelos agentes do Estado não pela comunidade como seria democraticamente, e investido de autoridade perante os moradores de cada região. Ele gozava e goza, inclusive, de poder coercitivo, muitas vezes materializados nas temidas polícias indígenas. Ainda hoje, continua muito mais planejado esse temor.

Como a forma que repercutiu essa figura tão temido o capitão, tirou muita autonomia de muitas famílias e rezadores. Desde então, essa preferência demonstra que o capitão era a figura indígena responsável por impor aos demais a ordem necessária para que os ideais assimilacionistas da política indigenista oficial pudessem ser postos em prática. Daí distanciou-se da importância de diálogo que sempre se manteve juntos aos ñanderu. Ele planejou o trabalho fora do que era previsto para manter cultura e saberes indígena. Foi realmente uma armadilha que foi posta nessa parte de dar o poder para comunidade que tinha outro tipo de política, onde decide quais caminhos seguirão para melhorar os problemas em relação a saúde, meio ambiente, praticas culturais e religião.

O espaço para pratica de rituais indígenas foi aos poucos não foi mais considerados mais importantes para organização das comunidades

\section{A atuação da Missão Caiuá}

Após de muitas dificuldades que os Guarani/Kaiowá (Kaiowá e Guarani Nhandeva) enfrentaram, houve a presença missionária protestante e instalou-se na reserva de Durados, a Missão Evangélica Presbiteriana, mais conhecida como Missão Caiuá, em 1928, ano em que se concluiu a demarcação das reservas. Pastor americano Albert Maxwel, da Igreja Presbiteriana Americana, foi fundador da Missão Caiuá, o qual, quando visitou a região de Mato Grosso do Sul, percebeu não "haver” presença de igrejas entre os Guarani e aos Kaiowá.

O trabalho além de realizar entre os Guarani e os Kaiowá catequese estende-se e se apoia em dois suportes: o atendimento à saúde e o ensino escolar. A missão tornou-se o único local disponível para qualquer tipo de assistência. Convém ressaltar, que naquele momento a população indígena enfrentaram as precárias condições, por isso a missão tornou-se referência 
para essa população, entretanto, representava aos indígenas o único local em encontravam alguma forma de assistência.

Naquela época os indígenas enfrentavam muitos problemas em relação à saúde, as epidemias e a desnutrição provocaram inúmeras ações. A ocupação dos karai (não indígena) também resultou na rápida proliferação de doenças, como de tuberculose, DSTs, febre amarela, sarampo, etc. Se recorremos ao Schaden (1974, p. 9) citado por muitos pesquisadores afirmam que na Reserva de Dourados, a população "tem diminuído consideravelmente, sobretudo em conseqüência da tuberculose pulmonar e de outras doenças".

Em Te'ýi oikoha Te'ýikue ou (na reserva indígena Te'ýikue) a missão instalou-se ao lado da reserva numa área da fazenda que hoje conhecida como fazenda Joha, em (1928). Os indígenas ajudaram o primeiro pastor Daniel para construir a igreja, naquela época era feita de sapé, alguns grupos de homens buscavam do mato madeira mais viável para construção de casa, outro grupo arrancava sape, o trabalho, portanto, foi na base do coletivo posto pelo próprio indígena. A mulher indígena trabalhava como empregada doméstica enquanto que os homens trabalhavam fazendo serviço geral, o pagamento era um "vale compra" é denominada pelos indígenas daquela época "ordem" que eles recebiam para ir a um comercio para pegar mercadoria.

A mãe da minha vó Vitoria Moraes e seu marido e as demais pessoas foram às primeiras pessoas que frequentou o culto e se batizaram. Dia de domingo os membros e as membras da igreja marcavam presença. A oração era feita em voz baixa e as canções eram cantadas todos juntos, no entanto, naquela época as canções já eram em guarani. Até então as famílias indígenas não enfrentaram muitas dificuldades, porque tinha muita mata e animais silvestres para caçar, a maioria plantava e se mantinha através disso. Quando a pessoa da comunidade ficava doente a Missão dava assistência para levar até a Dourados para ser receber consulta medica.

Contudo a partir da delimitação da área pelas agencias externas, os diferentes ñembyaty'i pehengue (grupos familiares) de outros tekoha foram sobrepostos de maneira compulsória, assim ocasionou a superpopulação e equilíbrio de recursos naturais, "tendo como consequência a desconfiguração do tekoha, com a transformação em reserva" (BENITES, pp. 44-45).

Aos poucos a organização social tradicional foi mudando. Isso aconteceu devido com o contato permanente dos indígenas com os karai (homem branco). A doença como 
desnutrição, catapora, $h u^{\prime} u$ puku (tuberculose), avançaram muito, alguns faleceram devido o avanço dessas doenças, todavia a missão dava-lhes assistência para levar até Dourados onde poderia ser tratados as doenças, assim foram ao longo dos anos. Os fieis retribuíam a ajuda frequentando o oculto. Saindo da igreja, poderia ocasionar a perda de ajuda e assistência.

É importante destacar a partir daqui o objetivo da Missão Presbiteriana para trabalhar com os indígenas. Quando o Pastor americano Albert Maxwel veio à visita ao Estado do atual Mato Grosso do Sul, na sua lógica parecia não haver presença de igrejas entre os Guarani e aos Kaiowá, era preciso construir igreja para mostrar aos indígenas a "palavra de Deus" através da Bíblia, assim acreditava-se que será uma nova "forma" de seguir e servir o Tupã (Deus), assim aconteceu no atual reserva indígena Te’ýikue. Os seguidores mais antigos da reserva Te'ýikue comentam que, a atuação da Missão trouxe-lhes muitas mudanças, porque a "metodologia" usada pelo Pastor em guarani para pregar, orar e cantar facilitava muito aos membros a entender melhor sobre Deus. Sendo assim atraia muitos fieis para igreja. Outro fator que influenciava os seguidores indígenas era a ajuda que a Missão dava-lhes. Como por exemplo, roupas, serviços, escola, assistência à saúde e oportunidade para socializa-se com a sociedade não indígena. Falo de socializar-se com os karai, aprendendo a falar a língua deles, neste caso a língua portuguesa, etc.

Em resposta a esta ação perversa, uma pedagogia invisível tratou de reforçar cada vez mais suas práticas tradicionais, sendo assim, por meio da cosmologia e da ancestralidade foi que planejamos uma estrutura política para que o ava percebesse que o seu confinamento não era legítimo nem sua obediência, necessária. Pois a ancestralidade e a cosmologia garantia o entendimento que a política assimilacionista era genocida e aniquiladora da cultura.

\section{Impasses e estratégias atuais para superação do esvaziamento do papel das lideranças tradicionais e Retekoharizar os tekoha}

$\mathrm{Na}$ busca constante para enfrentar desafios atuais que a reserva apresenta, vários tipos de estratégias foram formadas para que possam continuar exercendo suas funções de ñanderu. Uma das estratégias que é participação na vida política do município. Lembro do senhor Hipolito Martins filho de um ex yvyra'ija candidatou-se para vereador em 1993, com intuito de tentar melhorar a sua comunidade e também criar projeto cultural, assim ele acreditou que os karai veriam a importância da cultural dos indígenas. Essa tentativa foi uma tentativa relevante para retekoharizar, isso é recompor coletivos, ativando vínculos de sociabilidade 
entre famílias e também com os espaços de ocupação tradicional. Criando um lugar de esperança, sustentável e de alegria para as crianças, jovens, mulheres.

Assim, no entanto, buscou-se a mostrar o valor religioso misturado com a cultura. Vale ressaltar que, naquele tempo existia um conflito de menoridade em relação aos ñanderu e ñandesy, a comunidade argumentou que eles eram macumbeiros, por isso o suicídio, a violência e miséria foram chegando às famílias guarani e kaiowá. Mas com a arma do disfarce, haja vista supracitada, buscou-se outro lugar para continuar praticando suas práticas rituais. Por exemplo, quando do trabalho nas fazendas, a frete de um trabalho pesado, primeiramente começa o jehovasa para que Deuses do cosmos possam protegê-los. Assim como, para dominar os cavalos é necessário utilizar-se um tipo de reza, caso esse trabalhador não dominar esta reza, corre risco de não conseguir realizar o trabalho.

$\mathrm{Na}$ usina para conseguir diária boa e não ser picado por cobras e insetos o rezador leva no bolso um amuleto que se chama "ponde", primeiramente é necessário fazer reza de sete dias, como também respeitar vários tipos de presságios, como por exemplos, antes de iniciar sua jornada de trabalho praticar jehovasa, respeitar pyharevegua jara, laose jara e putu jara. Assim, no entanto, os espíritos (ou jaras) não deixam qualquer tipo de doença aproximar-se dessa pessoa. Esse rezador que foi muito respeitado no meio da turma de trabalhador, também ensinava as demais pessoas que se interessavam em aprender.

Os homens ao retornarem à aldeia continuavam praticando e também repassava aos filhos esses conhecimentos. Mas, os evangélicos, portanto, não concordavam com isso, pregava que esse tipo de prática de bruxaria e não era adequado para vontade de Deus/Jesus Cristo. Os crentes iam à usina disputavam com essas práticas distribuindo votos para conseguir livramentos e prosperidades. Faziam campanha de sete dias, geralmente tinha mais ou menos 30 pessoas no culto, fazia no pátio do alojamento. A campanha poderosa era feita no mato ou no meio dos canaviais. Porém, mesmo assim, alguns procuravam o filho ou próprio rezador para receber o amuleto e também aprender a reza; só para se ter noção muitas vezes eram crentes, ou, os próprios fiéis da igreja que procuravam os encantamentos de yvyra'ija. Lembrando que a busca pela crença tradicional era feita escondido do pastor ou da/o integrante da igreja, pois, se alguns soubessem correria risco de levar punição e ser julgado pelos próprios patrícios.

Desde 1998 os mais velhos se interessam sobre o que seria educação indígena e o que a escola estava ensinando para os jovens, vale ressaltar que, nessa época o currículo diferenciado estava sendo discutida em Te'yikue, os professores, no entanto, começaram a 
explicar a importância também da comunidade na construção de currículo diferenciado. Assim eles faziam parte da política e no controle da escola, tanto que eles participaram para escolha de professora para dar aula.

O convívio com as lideranças tradicionais (ñanderu e ñandsy) que o processo escolar indígena possibilitou aos professores indígenas, proporcionou compreensão maior sobre saberes indígenas. Deste movimento foi criando um fio condutor para uma visão tradicional sobre a educação escolar indígena, numa perspectiva diferente, intercultural e positiva sobre um desafio para se preencher o espaço da escola. Já que, historicamente, o Estado desenvolveu mecanismos para a desvalorização do modo de ser Kaiowá e Guarani, como por exemplo, sua identidade, religião, cultura, artes e seus sonhos.

Na aldeia Cerrito, no Mbo'eroy tava okara rendy, município de Eldorado, em 2013, tive a oportunidade de acompanhar o Movimento dos Professores Indígenas, que discutiram para cada vez mais como seria os espaços de formação específica que com muita luta foi assegurado pelas instituições de formação de professores. Os rezadores estiveram sempre presentes, participando dos debates, dando sugestões necessárias para escola ter fundamento cultural indígena, onde possa respeitar e trabalhar cultura, religião, artes, danças, etc.,

No Fórum, a epistemologia indígena de reunião e educação fora mantido, assim, antes de iniciar sobre a questão indígena na aldeia, o rezador começa rezando para que possa trazer sorte e também muitas sabedorias para discutir os problemas sociais. Todos respeitam, até os crentes entravam na roda para mostrar às autoridades a existência da cultura, para mostrar e saber o que é uma escola indígena e aldeia.

Na retomada das terras tradicionais Pindo Roky, Te'yi Juçu e recentemente Tekoha ñandeva, kunumi (2013), os rezadores foram muito importantes, já que foram dias de muita luta e muita reza para conseguir permanecer nesses tekoha yma guare. De tudo isso, a melhor parte foi o envolvimento da comunidade com os rezadores que pela visão aparente das modificações sociais da aldeia, pareciam que estavam sendo esquecidos pelas grandes influências das igrejas pentecostais.

No entanto, neste episódio de luta, todos dependiam deles para ter coragem para enfrentar os desafios e espíritos maus. Percebe-se, então, que o esvaziamento do significado do nhanderu na comunidade, ocorreu por falta de diálogo entre várias organizações políticas e instituições religiosas. Mesmo com tanto impedimento e da distância os rezadores dessas instituições, eles sempre mantiveram sua postura estratégica. Tanto que as pessoas nos dias atuais estão convencidas de que há possibilidade de tornar a reserva em um tekoha, onde os 
jovens poderão aprender a cultura e sonhar como indígena, ou seja, viver com reciprocidade entre os pares, e recompor os coletivos que durante o processo de expulsão de seus tekoha foram desconstruídos.

Ativando vínculos de sociabilidade entre famílias, olhamos o interior da reserva Te’yikue e percebemos isso como referência para as demais famílias. Pois, quando algumas famílias entram em conflitos, os mais velhos chamam todos num dia de domingo para almoço ou para passar a tarde juntos, e aproveitando a presença de todos começam a contar como era a história da família, nesta ocasião já aproveita a referência da atualidade, onde apesar de tudo essas famílias de referências se esforçam para melhorar ou recuperar vínculos de sociabilidades entre eles e recuperar ocupação tradicional, do jeito indígena, sem prejudicar a terra, os animais, os rios, tendo também um vínculo de respeito aos jara.

\section{Considerações finais}

Como haja visto, o texto procurou elucidar o processo de retekoharização, a partir da figura central dos rezadores na ressocialização dos costumes da aldeia. Buscamos dar elementos para fazer conhecer as funções de ñanderu e ñandesy e sua importância na comunidade.

Para isso, os rituais de jeroky e jehovasa foram narrados, dentro de contextos diferentes, para fazer entender como surgiu, a partir das observações em diferentes contextos, situações e famílias. Deste modo, consegui perceber o motivo de fragmentação da sociedade Guarani Kaiowá, que teve durante a criação da reserva Te'yikue mediado pelo SPI a desarticulação dos nossos modos de vida. já que, a criação da reserva trouxe grande impacto à sociabilidade indígena, caso os rezadores, os sábios, as parteiras, raizeiros aceitassem a imposição/dominação de outra cultura.

Entendemos que se não fosse a atuação destes líderes tradicionais, os jovens não estariam lutando para retekoharizar a aldeia, pelos moldes da ancestralidade e cosmologia da cultura. A comunidade como toda não conseguiria ver a importância da sua cultura, tanto que os direitos conquistados na Carta Magna da Constituição Federal de 1998 foram alcançados graças a luta dos povos indígenas acompanhados e orientados pelos rezadores, sonhado que um dia que seria possível recuperar o Teko joja, Teko Porã, Teko Marangatu, Teko Katu, Teko py'a guapy, Teko mirĩ, Teko vy'a.

Muitas vezes os karai questionam sobre a forma de anseios dos indígenas de resgatar alguns teko fundamental do seu cosmos, mas convém lembrar que isso não partiu de qualquer 
jeito, existe todo processo espiritual que vem lá dos deuses do cosmos. Aos quais, os rezadores pedem força e sabedoria para trabalhar de forma objetiva na comunidade, tendo em vista que teko karai já se fez presente desde sua criação, através de reza consegue identificar quais perigos irão enfrentar numa comunidade e também para expulsar todo perigo que poderá impedir a conquista futura.

As pesquisas foram feitas com minha comunidade da reserva Te'yikue, onde muitos rezadores como Lidio Sanches, Florêncio Barbosa, Machu Leona, etc., trabalham para mostrarem que é possível retekoharizar a reserva, onde a escola e lideranças políticas, segundo eles, são imprescindíveis para essa missão. A maioria das pessoas poderiam se contentar em ser produtos da reserva do SPI, ou seja, em ser moradores de uma área de acomodação e assim, não seria possível torna-la um tekoha do jeito indígena, de cultura, de religião, de remédio tradicional, da língua, da poesia, da filosofia um lugar de laboratório de conhecimento indígena. Por isso, retekorizar é uma conjugação forte da cultura contemporânea do ava guarani, pois vem contribuindo para romper esse paradigma de que na reserva não há mais cultura, de que não há mais possibilidade de chamá-la de um tekoha, e que as aldeias são meros bairros dos mundo periférico das cidades e interiores.

Conforme descobrimos na pesquisa, a maioria das pessoas da comunidade naturalizam a proposta da reserva (conferida pelo SPI), talvez por isso parecem desacreditar na proposta dos rezadores e acabam se perdendo nesse sonho de karai. Falo sonho de karai, porque alguns querem falar somente a língua português, e ensina os seus filhos essa língua e alimenta o preconceito sobre família que tem menos contato com essa língua ou que quer guardar mais elementos da cultura. Creio que essas coisas criam algumas dificuldades para a socialização. Não falo que isso é negativo, é bom que os indígenas aprendam a língua dominante, porém isso não precisa ser um dado de desunião entre os patrícios. Tão pouco o caso inverso. Apesar de este não ter sido o escopo do trabalho.

O que procuramos abordar foi o histórico da reserva, para demonstrar o processo de resistência à política de assimilação, que desde que a Terra indígena foi criada e, durante décadas, buscaram-se meios de resistência e reconstrução dos modos de vida, ou ñande reko. O que foi encontrado pela forma de retekoharizar o território, isto é, subverter o projeto de reserva, que correspondeu ao formato de confinamento e aniquilação, para restabelecer o sonho de viver nossa cultural.

Convém ressaltar que Te'yikue sempre foi um tekoha, assim como confirma a ancestralidade que é buscado da memória dos mais velhos e sábios da aldeia. Com modelo 
adotado pelo SPI, muitos problemas foram se trazidos para dentro da aldeia, acirrando conflitos entre várias famílias.

Mas pelo ato de retekoharizar pude discutir esse conceito cultura e das diversas formas de ser movimentado pelos indígenas. O fenômeno mostrou-se totalmente contemporâneo, denotando que a cultura ancestral também é atualizada na contemporaneidade. Isso mostra que o indígena não é um ser do passado, como os estereótipos do senso comum querem determinar. Mas que, a cultura é atualizada e debatida com a figura central dos líderes tradicionais. Achei muito importante este tipo de descoberta, uma vez que, torna-se cada vez mais relevante para pesquisadores indígenas e não-indígenas, para que possam entender os signos contemporâneos da nossa cultura. Por isso foi que tratei esse tema com bastante cautela, até porque pensar a reserva sem questionar, corre-se o risco de cada vez mais o Estado continuar praticando de forma oculta seu projeto de assimilação e injustiça, não respeitando os sonhos e objetivos dos rezadores para tekoha. Também cabe apontar que o comportamento pacífico e resiliente dos povos Guarani e Kaiowá foi identificado por alguns antropólogos a chamarem a aldeia de área de acomodação.

Em reserva Te'ýikue, na experiência de vida em reserva, que já se aproxima de um século, muitas parentelas já vivenciaram muitas transformações nas relações com os brancos, refletindo sobre as relações e sociabilidade entre famílias.

Nesse ponto descrevi como foi e como era o papel dos rezadores para continuar defendendo sua cultura e lutar para permanecer como índio, tanto que hoje tudo depende deles para recuperação dos saberes tradicionais e pratica da religião de forma dialogada com as igrejas da reserva Te'yikue, assim colorir esse tekoha de cultura indígena, podendo cada vez mais mostrar que é possível retekoharizar.

\section{Bibliografia}

BENITES, Tonico. A escola indígena na ótica dos Ava Kaiowá: impactos e interpretações indígenas. 2009. 106f. Dissertação (Mestrado em Antropologia Social) - Programa de PósGraduação em Antropologia Social do Museu Nacional da Universidade Federal do Rio de Janeiro, Rio de Janeiro, RJ.

BENITES, Tonico. Rojeroky hina ha roike jevy tekohape (Rezando e lutando): o movimento histórico dos Aty Guasu dos Ava Kaiowa e dos Ava Guarani pela recuperação de seus tekoha. 2014. 270f. Tese (Doutorado em Antropologia Social) - Universidade Federal do Rio de Janeiro, Rio de Janeiro, RJ. 
BONIN, Iara Tatiana. E por falar em povos indígenas...: quais narrativas contam em práticas pedagógicas? 2007. 220f. Tese (Doutorado em Educação) - Universidade Federal do Rio Grande do Sul, Porto Alegre, RS.

BRAND, Antonio. Os complexos caminhos da luta pela terra entre os kaiowá e guarani no MS. In: Tellus, ano 4, abr. 2004, n. 6, p. 137-150. Campo Grande - MS: UCDB, 2004.

BRAND. Antonio Jacó. O confinamento e seu impacto sobre os Paì-Kaiowá. 1993. $274 f$. Dissertação (Mestrado em História) - Pontifícia Universidade Católica do Rio Grande do Sul, Porto Alegre, RS.

BRAND. Antonio Jacó. O impacto da perda da terra sobre a tradição kaiowá/guarani: os difíceis caminhos da palavra. 1997. 382f. Tese (Doutorado em História) - Programa de PósGraduação em História da Faculdade de Filosofia a e Ciências Humanas, Pontifícia Universidade Católica do Rio Grande do Sul, Porto Alegre, RS.

COLMAN, Rosa Sebastiana. Considerações sobre Território para os kaiowá e guarani. In: Tellus, ano 8, n. 15, p. 153-174, jul./dez. Campo Grande: UCDB, 2008.

GOTTMANN, Jean. A Evolução do Conceito de Território. Boletim Campineiro de Geografia, v. 2, n. 3. Campinas: 2012. Tradução: Isabela Fajardo e Luciano Duarte. Revisão: Fabricio Gallo.

MURA, Fabio. A procura do "bom viver": território, tradição de conhecimento e ecologia doméstica entre os Kaiowá. 2006. 504f. Tese (Doutorado em Antropologia Social) Universidade Federal do Rio de Janeiro, Rio de Janeiro, RJ.

PEREIRA, Levi Marques. Imagens Kaiowá do sistema social e seu entorno. 2004. 403f. Tese. (Doutorado em Antropologia) - Programa de pós graduação em Antropologia Social, Universidade de São Paulo, São Paulo, SP.

PIMENTEL, Spensy Kmitta. Aty Guasu, as grandes assembleias Kaiowa e Guarani: os indígenas de MS e a luta pela redemocratização do país, [s.d.]. (no prelo).

PIMENTEL, Spensy Kmitta. Elementos para uma teoria política kaiowá e guarani. 2012. 364f. Tese (Doutorado em Antropologia Social) - Faculdade de Filosofi a, Letras e Ciências Humanas, Universidade de São Paulo, São Paulo, SP.

SANTOS, Milton; e SILVEIRA, María L. O Brasil - Território e Sociedade no início do Século XXI. Rio de Janeiro: Record, 2001.

SOUZA, Marcelo J. L. de. O Território: Sobre Espaço e Poder, Autonomia e Desenvolvimento. In: CASTRO, Iná E. de; GOMES, Paulo C. da C.; e, CORRÊA, Roberto L. Geografia: Conceitos e Temas. 15ª Ed. Rio de Janeiro: Bertrand Brasil, 2012.

THOMAZ DE ALMEIDA, Rubem Ferreira. Relatório da Área Indígena Pirakua, MS. Brasília: FUNAI, 2001. [Mimeo]. 
BENITES, Eliel. Oguata Pyahu (Uma Nova Caminhada) no Processo de Desconstrução e Construção da Educação Escolar Indígena da Aldeia Te’ýikue. Campo Grande, 2014, 130 p. Dissertação (Mestrado) Universidade Católica Dom Bosco. 